\title{
Elektrikli Araç Şarj Cihazlarında Kullanılan Güç Faktörü Düzeltmeli Yükseltici Tip Dönüştürücünün Analizi
}

\author{
Aybüke Özdentürk*, Ramazan Akkaya \\ *Elektrik-Elektronik Mühendisliği/ Mühendislik Ve Doğa Bilimleri Fakültesi, Konya Teknik Üniversitesi, Türkiye (ORCID: 0000-0001-8282-1934) \\ Elektrik-Elektronik Mühendisliği/ Mühendislik Ve Doğa Bilimleri Fakültesi, Konya Teknik Üniversitesi, Türkiye (ORCID: 0000-0002-6314-1500) \\ ( $1^{\text {st }}$ International Conference on Computer, Electrical and Electronic Sciences ICCEES 2020 - 8-10 Ekim 2020)
}

(DOI: $10.31590 /$ ejosat.804561)

\begin{abstract}
ATIF/REFERENCE: Özdentürk, A. \& Akkaya, R. (2020). Elektrikli Araç Şarj Cihazlarında Kullanılan Güç Faktörü Düzeltmeli Yükseltici Tip Dönüştürücünün Analizi.Avrupa Bilim ve Teknoloji Dergisi, (Özel Sayı), 308-314.

$\ddot{O} z$

Gelecekte fosil yakıtlı araçların yerini alacağı tahmin edilen elektrikli araç teknolojisinde batarya şarjı en önemli konulardan birisidir. Doğru ve verimli bir şarj işlemi için batarya şarj modülü iyi tasarlanmalı, yaratacağı olumsuz etkiler giderilmelidir. Şarj modülünün olumsuz özelliklerinden birisi bağlı olduğu şebeke üzerinde yaptığı bozucu etkilerdir. Bu etkiler, düşük güç faktörü ve çekilen şebeke akımında oluşan yüksek harmonik distorsiyondur. Bu çalışmada şebekeden çekilen akımın harmonik içeriğinin azaltılması ve bire yakın güç faktörü elde edilmesi amacıyla 1. seviye $(3 \mathrm{~kW})$ on board batarya şarjı için yükseltici (boost) tip dönüştürücü içeren tek fazlı Güç Faktörü Düzeltici (PFC) devre yapısı incelendi. Dönüştürücü Matlab/Simulink ortamında simule edildi. Şebeke tarafında oluşan dalga şekillerinin, şebeke akımı harmonik yüzdesi, güç faktörü ve sistemin verim değerlerinin PFC'siz yapıya göre oldukça iyileştirilmiş olduğu görüldü.
\end{abstract}

Anahtar Kelimeler: Güç Fakörü, PFC, Yükseltici Dönüştürücü, Harmonik Bozulma

\section{Analysis of Boost Type Converter with Power Factor Correction Used in Electric Vehicle Chargers}

\begin{abstract}
Battery charging is one of the most important issues in electric vehicle technology, which is predicted to replace fossil fuel vehicles in the future. For a correct and efficient charging process, the battery charging module should be well designed and its negative effects should be eliminated. One of the negative features of the charging module is its disruptive effects on the grid to which it is connected. These effects are low power factor and high harmonic distortion in the drawn grid current. In this study, in order to reduce the harmonic content of the current drawn from the grid and to obtain a power factor close to one, the single-phase Power Factor Correct (PFC) circuit structure including a boost type converter for 1st level $(3 \mathrm{~kW})$ on board battery charging was examined. The converter was simulated in Matlab / Simulink. It was observed that the waveforms on the grid side, harmonic percentage of the grid current, the power factor and the efficiency values of the system were considerably improved compared to the structure without PFC.
\end{abstract}

Keywords: Power Factor, PFC, Boost Converter, Harmonic Distortion

\section{Giriș}

Fosil kökenli yakıtların sınırlı rezervlere sahip olması, yüksek maliyeti, yakılmaları sonucu ortaya çıkan zararlı emisyonlar ve sera gazlarının çevre üzerine etkileri ulaşım sektöründe bir değişimi gerektirmiş ve elektrikli araçlar üzerinde yapılan çalışmaların yoğunlaşmasına sebep olmuştur. Elektrikli araç teknolojisinin gelişmesinin önündeki en önemli sorunlardan birisi elektrik enerjisinin depo edildiği bataryaların şarj işlemidir. Şarj işlemi gerçekleştirilirken en verimli şekilde ve en kısa sürede şarj hedeflenir. Ancak bu durum sağlanmaya çalışılırken şarj modülü şebekeden sağlıklı bir şekilde enerji çekememeye ve şebekede bozucu etkiler yaratmaya başlar. Doğru bir şarj için bu etkilerin giderilmesi zorunludur. 
Şarj işlemi temel olarak iki aşamadan oluşur. İlk aşama şebekeden alınan AC gerilimin doğrultulup DC gerilimin elde edildiği doğrultucu kısmıdır. İkinci aşama ise elde edilen DC gerilimin istenilen şarj seviyesine göre regüle edilip bataryaya aktarıldığı DCDC dönüştürücü kısmıdır (Tinğ et al., 2015). Şebekeye bağlı olan şarj modülü bu dönüşümleri yaparken şebekeden çekilen akımda yüksek harmonik distorsiyona ve birim değerde olması istenen güç faktörü değerinde düşüşe sebep olur (Monteiro et al., 2017). Bu iki etki de , özellikle elektrikli araçlar gibi yüksek güç değerlerine ihtiyaç duyan yükler bağlıyken, şebeke açısından sorun yaratır. Yüksek harmonik distorsiyon ısınmalara, enerji kayıplarına, mekanik elemanların çalışmasında bozulmaya sebep olarak şebekeye bağlı diğer yüklerin çalışmasını olumsuz etkiler. Düşük güç faktörü ise şebekeden çekilen gücün etkin bir şekilde ve verimli olarak kullanılmamasına neden olur. Güç faktörünün düşük olması daha fazla reaktif güç anlamına gelir. Bu olumsuzlukları gidermek için farklı PFC'li aktif devreler kullanılarak doğrultma aşamasında harmonik etki azaltılır ve güç faktörü düzeltilir (Mohanty et al., 2016). Elde edilen doğrultulmuş gerilim bir kondansatör ile filtrelenir. Daha sonra DC-DC dönüştürücü ile regüle edilen gerilim batarya şarjı için kullanılır. Şekil 1'de temel PFC'li şarj yapısı gösterilmiştir (Gong \& Powertrain, n.d.).

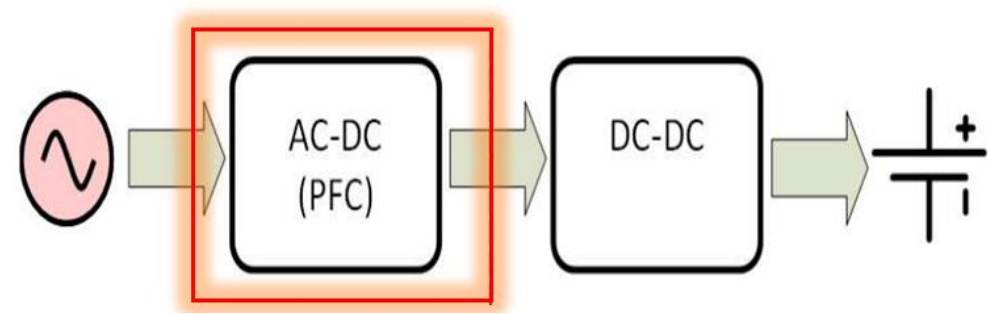

Şekil 1.Temel PFC'li şarj yapısı

\section{Materyal ve Metot}

\subsection{Güç Faktörünün Düzeltilmesi Ve Akım Harmoniklerinin Azaltılması}

Güç faktörünün düzeltilmesi, şebekeden çekilen akım dalga şeklinin sinüse yaklaştırılması ve çekilen reaktif gücün elimine edilmesi demektir. Güç faktörü $(\cos \varphi)$ değerinin küçük olması şebekeden çekilen reaktif gücün büyük olduğu anlamına gelir. Yani sistem aynı aktif gücün yapacağı iş için şebekeden daha fazla akım çeker. Reaktif gücün azaltılıp, güç faktörünün (cos $\varphi$ )'nin yükseltilmesi (1'e) işlemine güç faktörünün düzeltilmesi (PFC) denir.

Sinüzoidal olmayan bir kaynaktan çekilen akım, temel bileşen ve harmoniklerden oluşur. Efektif akım $\left(\mathrm{I}_{\mathrm{f}}\right)$, temel akım $\left(\mathrm{I}_{\mathrm{f} 1}\right)$ ve toplam harmonik akım $\left(\mathrm{I}_{\mathrm{fth}}\right)$ olmak üzere,

$I_{f}=\sqrt{I_{f 1}{ }^{2}+I_{f t h}^{2}}$

$I_{N}$, n. harrmonik akım olmak üzere,

$\mathrm{I}_{\mathrm{fth}}=\sqrt{I_{2}^{2}+I_{3}^{2}+{I_{4}}^{2} \ldots+I_{N}^{2}}$

Toplam harmonik distorsiyon:

$\mathrm{THD}=\frac{I_{f t h}}{I_{f 1}}=\sqrt{\sum_{n=2}^{N}\left(\frac{I_{n}}{I_{f 1}}\right)^{2}}$

Kayma Faktörü : $\mathrm{DF}=\cos \varphi 1$

Güç faktörü: $\quad \mathrm{PF}=\frac{\mathrm{P}}{\mathrm{S}}=\frac{I_{f 1}}{I_{f}} \mathrm{DF}$

olarak elde edilir.

Harmonik içeren sistemlerde (1-5) nolu denklemlerden anlaşılacağı gibi harmonik bileşenlerin artış1 güç faktörünü düşürücü etki gösterir. Tasarlanan PFC'li doğrultma devreleri harmonikleri azaltarak girişten sinüs dalga formunda akım çekmeyi ve bire yakın güç faktörü elde etmeyi amaçlar. Şekil 2(a)'da gösterilen tek fazlı köprü doğrultucu Matlab/Simulink ortamında simüle edilmiş, giriş gerilim ve akımlarının değişimleri Şekil2(b)'de, Şekil2(c)'de ise akım sinyalinin harmonik değerleri verilmiştir. Şekil 2(c) 'de görüldüğü gibi bu devrede şebekeden çekilen akımın harmonik distorsiyonu \%120'dir. Güç faktörü değeri 0,84, verimi \% $\%$ 70’dir. Bu değerler sağlıklı çalışma için kabul edilemez seviyededir. Bu nedenle IEEE 519, IEC 1000-3 ve IEC-6000-3-2 standartlarına uygun şekilde düzenleme yapacak dönüştürücü yapıları kullanılmalıdır. Bu yapıların temelinde ise yükseltici tip PFC devresi vardır. 


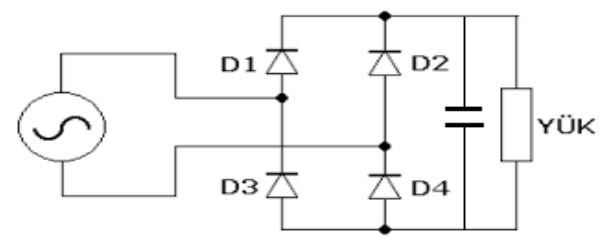

(a)

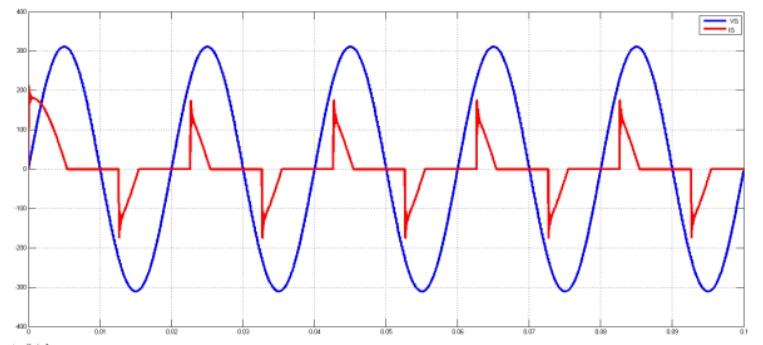

(b)

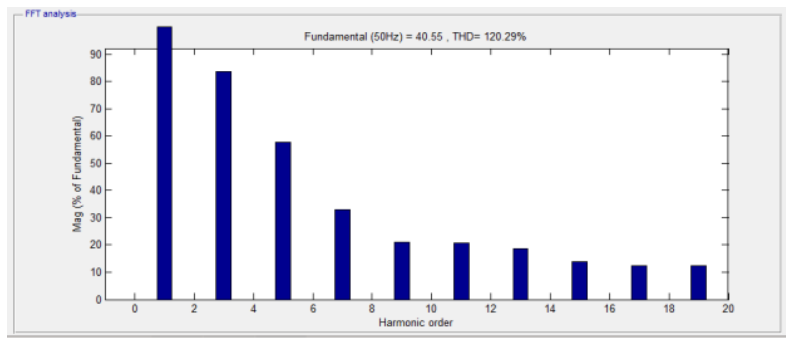

(c)

Şekil 2. a) Köprü doğrultucu devre şeması b) Giriş gerilimi ve giriş akımı değişimi c) Giriş akımı harmonik bileşen yüzdesi

\subsection{Yükseltici Tip PFC Dönüştürücü}

\subsubsection{Devrenin Çalışma Modları}

En fazla kullanılan tek yönlü aktif doğrultucu PFC devresidir. Şekil 3’te görüldüğü gibi bir diyot köprü devresinin ardına eklenen yükseltici tip bir DC-DC dönüştürücüden oluşur. Şekil 3(a)'da kaynağın pozitif yarım peryodunda S1 anahtarı iletimdeyken devrenin çalışma yapısı gösterilmiştir. D1 ve D2 diyotları üzerinden dolaşan akım L1 bobinini şarj eder. Çıkış kondansatörü yükü besler. S1 anahtarı kesime girince Şekil 3(b)'de gösterilen çalışma gerçekleşir. Kaynak ve L1 bobini yükü besler, L1 deşarj olurken çıkış kondansatörü şarj olur. Negatif yarım periyotta ise D3 ve D4 diyotları üzerinden aynı durum tekrarlanır. Boost dönüştürücünün ön uç indüktörü nedeniyle giriş akımı sürekli ve pürüzsüzdür. Çıkış kondansatörü çıkış gerilimi üzerindeki dengesizlikleri azaltır.

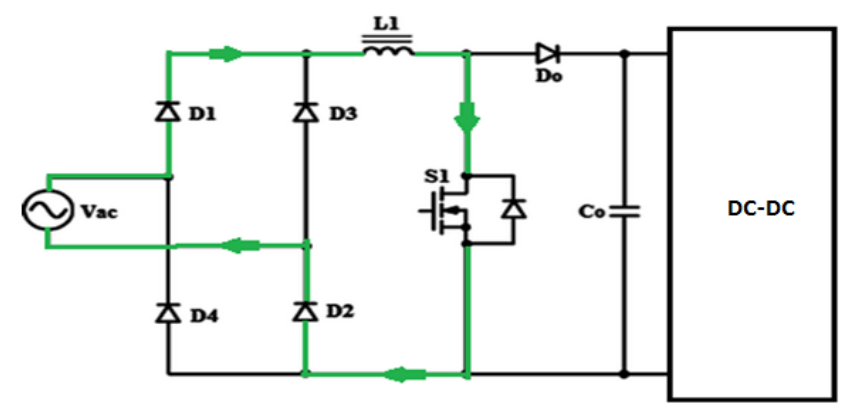

(a) 


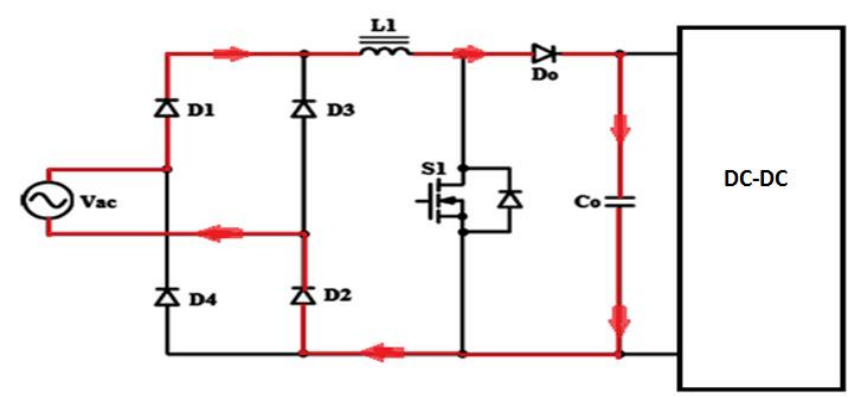

(b)

Şekil 3.Pozitif yarım periyotta çalı̧̧ma devre şemaları a)Anahtar on durumda b) Anahtar off durumda

Yükseltici tip PFC devresinin önemli özellikleri aşağıda sıralanmıştır (Praneeth \& Williamson, 2018)( Musavi et al., 2010).

- Tek bir anahtar kullanıldığından kontrolü ve dizaynı kolaydır.

- Eleman sayısı azdir.

• Güç faktörünü ideale yakın düzeltir.

- Çıkış gerilimi, daima giriş gerilimi tepe değerinden büyüktür.

- Diğer PFC devreleriyle karşılaştırıldığında çıkış kondansatörü akım dalgalanmaları daha yüksektir. Elemanlarda yüksek gerilim stresi vardır.

- Köprüsüz PFC devreleriyle karşılaştırıldığında köprü doğrultucu barındırdığından küçük güç değerlerinde daha verimli çalışır. Çünkü yüksek güçlerde diyotların ters toparlanma süresi daha fazla 1sı yayılımına sebep olur, kayıplar artar verim düşer.

- Sayılan bazı negatif özelliklerine rağmen klasik yükseltici yapısı PFC' nin temelidir.

\subsubsection{Devre Elemanlarının Belirlenmesi}

Devrede kullanacak elemanların özellikle endüktör değerinin belirlenmesi dönüştürücünün doğru çalışmasını etkileyen en önemli noktadır. Bu parametrelerin belirlenmesinde aşağıdaki denklemler kullanılmıştır (Musavi et al., 2010). $\mathrm{V}_{\mathrm{C}}$ çıkış gerilimi, $\mathrm{V}_{\mathrm{Gm}}$ giriş gerilimi tepe değeri olmak üzere D anahtar kapı sinyalinin görev oranı :

$D=\frac{V_{C_{C}}-V_{G m}}{V_{\zeta}}$

$P_{C}$ çıkış gücü, $P_{G}$ giriş gücü, $\eta$ verim olmak üzere giriş akımı tepe değeri:

$I_{G m}=\frac{\sqrt{2} * P_{C}}{\mathrm{\eta}^{*} V_{G}}$

$P_{G}=\frac{P_{C}}{\eta}$

\% $\mathrm{I}_{\mathrm{L}}$ endüktör akımının dalgalanma yüzdesi olmak üzere akım dalgalanma miktarı:

$\Delta I_{L}=\% I_{L} * I_{G m}$

Endüktör değeri:

$L_{1}=\frac{V_{G m} * D}{f_{s} * \Delta \mathrm{I}_{L}}$

Burada $f_{s}$ anahtarlama frekansıdır. Anahtarlama frekansı arttıkça bobin değeri düşer. $\Delta t$ girişe uygulanan gerilimin frekansına bağlı olarak ayarlanmak üzere çıkış kondansatörü $\mathrm{C}_{C}$ :

$C_{C}=\frac{2 * P_{C} * \Delta t}{V_{C}{ }^{2}-V_{G m}{ }^{2}}$ 
Olarak verilir ve çıkış dalgalılığını azaltmak için kullanılır, $\mathrm{C}_{C}$ değeri büyüdükçe çıkış dalgalanma miktarı azalır ancak giriş akımında oluşan harmonik artar.

\subsubsection{Kontrol Yöntemi}

DC-DC dönüştürücülerde, tepe akım kontrolü, ortalama akım kontrolü, histerisiz kontrol gibi kontrol yöntemleri kullanılmaktadır. $\mathrm{Bu}$ çalı̧̧mada daha iyi giriş akımı elde edilebildiği için ortalama akım kontrolü yöntemi tercih edilmiştir. Kontrol yapısında biri iç biri dış olmak üzere iki kontrol çevrimi vardır. Çıkıştan ölçülen gerilim, referans gerilim değeriyle karşılaştırılır ve daha sonra PI kontrol uygulanır. Kontrolör çıkışı ile köprü doğrultucu çıkış gerilimi çarpılır ve referans akım elde edilir. Bu dış çevrimden elde edilen sonuç referans akım değeri olarak iç kontrol çevriminde ölçülen bobin akımıyla karşılaştırılır. Buradan elde edilen hata, üçgen taşıyıcı dalgayla karşılaştırılarak anahtarların kapı sinyalleri oluşturulur (Ancuti et al., 2014). Bu şekilde çıkışta sabit gerilim, girişte ise sinüzoidal akım elde edilecek şekilde kontrol tamamlanır. Sürekli akım modu, kesintili akım modu, kritik mod olmak üzere farklı modlarda çalışma sağlanır (Inamdar et al., 2019). Sürekli akım modunda çalışma için bobin akımının grafiği Şekil 4'te gösterilmiştir. $\mathrm{Bu}$ modların belirlenmesinde anahtarın görev oranı D rol oynar. Sürekli akım modunda akım değeri sıfıra inmez ve Şekil 4'te görüldüğü gibi süreklidir.

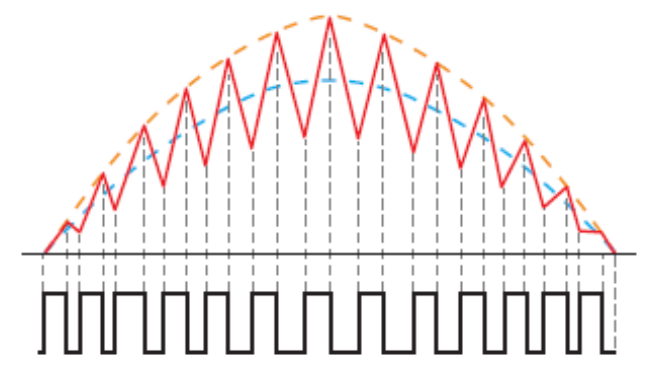

Şekil 4. Sürekli akım modunda bobin akımı ve anahtar kapı sinyali

\subsection{Yükseltici Tip Pfc Dönüştürücü Simülasyon Çalışmaları}

Bu çalışmada, seviye 1 batarya şarjı için uygun olan $3 \mathrm{~kW}$ çıkış gücü, $440 \pm \% 5 \mathrm{~V}$ sabit çıkış gerilimi elde edilecek şekilde yükseltici PFC devresi analiz edildi. Ortalama akım kontrol yöntemi ile kontrol gerçekleştirildi. (6-11) nolu denklemler yardımıyla devrede kullanılacak parametreler belirlendi. $45 \mathrm{kHz}$ anahtarlama frekansında hesaplanan parametreler Tablo 1'de gösterilmiştir.

Tablo 1.Hesaplanan parametreler

\begin{tabular}{|c|c|c|c|}
\hline $\mathrm{V}_{\mathrm{C}}$ & $\mathrm{L}_{1}$ & $\mathrm{C}_{\mathrm{C}}$ & $\mathrm{f}_{\mathrm{S}}$ \\
\hline $440 \mathrm{~V}$ & $4,8 \mathrm{mH}$ & $820 \mu \mathrm{F}$ & $45 \mathrm{kHz}$ \\
\hline
\end{tabular}

\subsubsection{Bulgular}

Şekil 5’te Matlab/Simulink ortamında kurulan devre ve kontrol yapısı gösterilmiştir. Şekildeki devrenin çıkışından 6,86 A akım ve 442 V çıkış gerilimi ölçülmüştür.

Şekil 6'da giriş gerilimi, giriş akımı ve çıkış gerilimi dalga şekilleri verilmiştir. Giriş akımı amaçlandığı gibi sinüs şeklindedir ve giriş gerilimini takip etmektedir. Çıkış gerilimi, referans gerilim değerini yakalamış ve gerilim dalgalanması $10 \mathrm{~V}$ civarındadır. Giriş akımı THD değeri Şekil 7'de gösterildiği gibi \%6,52 olarak elde edilmiştir. 


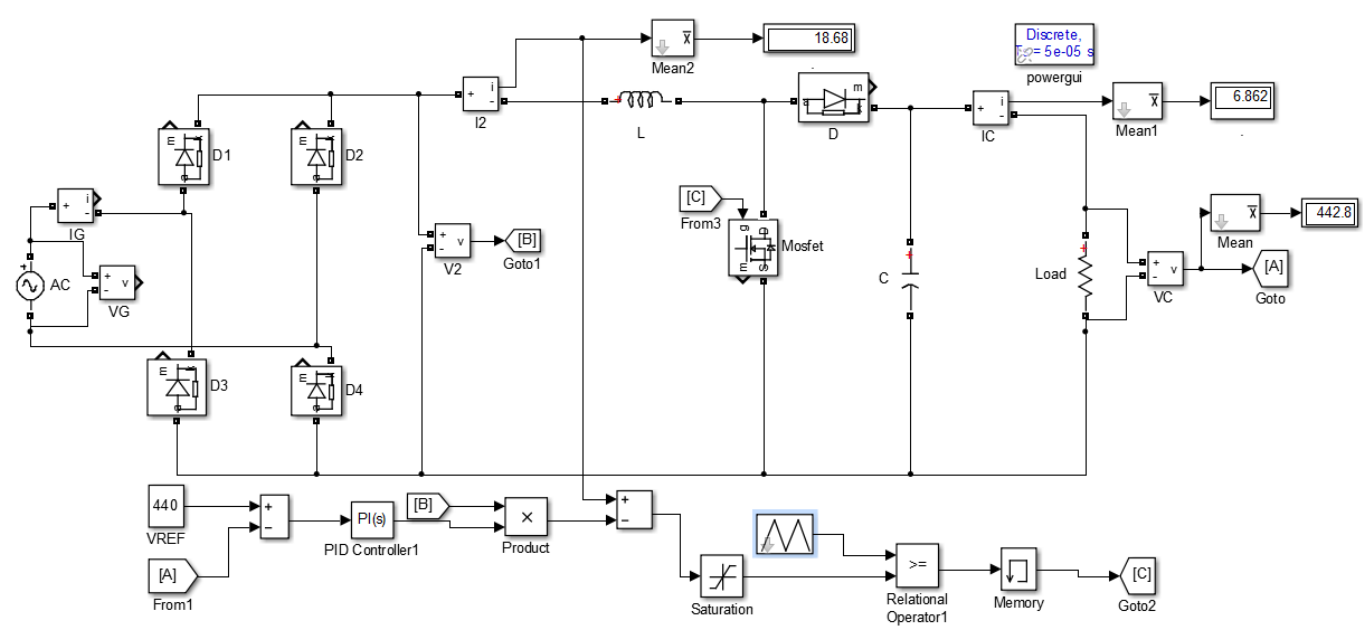

Şekil 5. Matlab/Simulink’te klasik boost pfc devre modeli

Tablo 1'de ki verilere göre tasarlanan yükseltici tip PFC devresi simulasyonu sonucunda Tablo 2'de gösterilen verim ve güç faktörü değerlerine ulaşılmıştır.

Tablo 2. Tasarlanan devrenin verim, THD ve güç faktörü değerleri.

\begin{tabular}{|c|c|}
\hline $\mathrm{P}_{\mathrm{C}}$ & 3037 \\
\hline $\mathrm{P}_{\mathrm{G}}$ & 3167 \\
\hline Güç Faktörü & 0,998 \\
\hline Verim & $\% 96$ \\
\hline THD & $\% 6,52$ \\
\hline
\end{tabular}

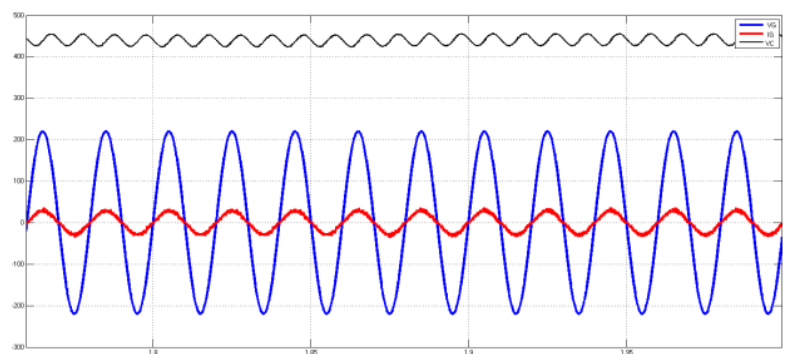

Şekil 6.Giriş gerilimi, giriş akımı ve çıkış gerilimi dalga şekilleri

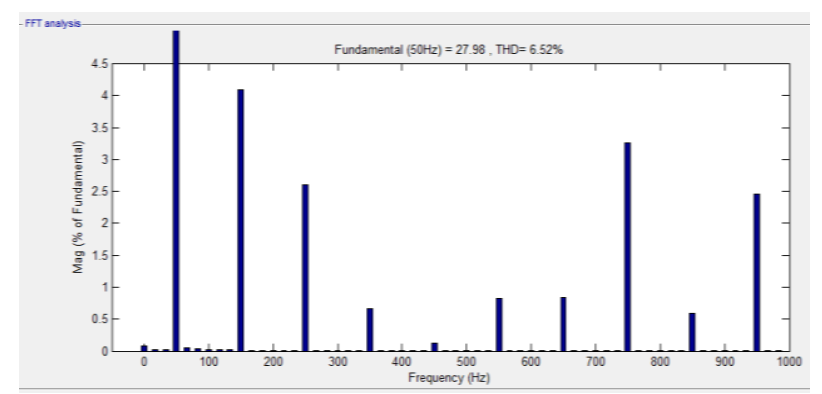

Şekil 7. Giriş akımı harmonik içeriği

\section{Sonuç}

Bu çalışmada, batarya şarjında kullanılan dönüştürücülerin şebeke üzerinde yaptığı olumsuz etkilerin giderilmesi için tasarlanan yükseltici (boost) tipi PFC devresi analiz edilmiştir. Elde edilen analiz sonuçları PFC li olmayan doğrultucu ile karşılaştırıldığında verim değerinin arttığı, giriş akımının sinüs şeklinde olduğu ve THD'sinin \%120'den \% 6,52'ye düştüğü, güç faktörü değerinin 0,99'a 
ulaştığı görüldü. Bu analiz sonucunda boost tipi PFC dönüştürücü yapısının AC şebekeden çekilen akımın THD’sini önemli ölçüde azalttığı ve güç faktörünü iyileştirdiği böylece elektrikli araç batarya şarjları için kullanılabilir olduğu anlaşılmıştır.

\section{Kaynakça}

Akın, B. (2012). Elektrikli Arabalarda Kullanılan Li - ion Akülerin Tek Fazdan Hızlı ve Verimli Şarjı için Güç Faktörü Düzeltmeli Yükselticilerin Karşılaştırması. EMO Bilimsel Dergi, Cilt 2, Sayı 4.

Ancuti, M. C., Svoboda, M., Musuroi, S., Hedes, A., Olarescu, N. V., \& Wienmann, M. (2014). Boost interleaved PFC versus bridgeless boost interleaved PFC converter performance/efficiency analysis. 2014 International Conference onApplied and Theoretical Electricity, ICATE 2014 - Proceedings, 2-7. https://doi.org/10.1109/ICATE.2014.6972651

Gong, X., \& Powertrain, S. E. M. (n.d.). Designing 6 . 6kW Bidirectional HEV / EV On-Board-Charger with SiC and Embedded Technologies.

Inamdar, S., Thosar, A., \& Mante, S. (2019). Literature Review of 3.3kW on Board Charger Topologies. Proceedings of the 3rd International Conference on Electronics and Communication and Aerospace Technology, ICECA 2019, 276-281. https://doi.org/10.1109/ICECA.2019.8822063

Mohanty, P. R., Panda, A. K., \& Das, D. (2016). An active PFC boost converter topology for power factor correction. 12th IEEE International Conference Electronics, Energy, Environment, Communication, Computer, Control: (E3-C3), INDICON 2015. https://doi.org/10.1109/INDICON.2015.7443118

Monteiro, V., Pinto, J. G., Fernandes, J. C. A., \& Afonso, J. L. (2017). Experimental comparison of single-phase active rectifiers for EV battery chargers. VEHITS 2017 - Proceedings of the 3rd International Conference on Vehicle Technology and Intelligent Transport Systems, Vehits, 419-425. https://doi.org/10.5220/0006391804190425

Musavi, F., Eberle, W., \& Dunford, W. G. (2010). Efficiency evaluation of single-phase solutions for AC-DC PFC boost converters for plug-in-hybrid electric vehicle battery chargers. 2010 IEEE Vehicle Power and Propulsion Conference, VPPC 2010. https://doi.org/10.1109/VPPC.2010.5729187

Praneeth, A. V. J. S., \& Williamson, S. S. (2018). A Review of Front End AC-DC Topologies in Universal Battery Charger for Electric Transportation. 2018 IEEE Transportation and Electrification Conference and Expo, ITEC 2018, 916-921. https://doi.org/10.1109/ITEC.2018.8450186

Tinğ, N. S., Aksoy, İ., \& Şahin, Y. (2015). Elektrikli Araçların Batarya Şarjinda Kullanılan Gü̧̧ Faktörü Düzeltmeli Klasik Ve Interleaved Yükseltici Türü Dönüşı̈̈rücülerin Karşılaştırılması. 1-6. 